\title{
The effect of vibration on the possibility of a threat to the health of workers on scaffolding
}

\author{
Jacek Grosel ${ }^{1}$, Marek Sawicki ${ }^{1}$, Wojciech Sawicki ${ }^{1}$, Mariusz Szóstak ${ }^{1}$, and Zbigniew \\ Wójcicki ${ }^{1, *}$ \\ ${ }^{1}$ Wroclaw University of Science and Technology, Faculty of Civil Engineering, 50-370 Wroclaw, \\ Wyb. Wyspianskiego 27, Poland
}

\begin{abstract}
Scaffoldings are specific structures that are particularly predisposed to vibrations. The article analyses the impact of vibrations induced by human activity on the stage for the possibility of a threat to the health of workers working in these structures. The aim of the article is to present experimental research.
\end{abstract}

\section{Introduction}

In considerations of workplace safety, the human factor is the most important one, as humans play a triple role in the process of the accident: as decision maker, the one who causes the accident and, above all, as the victim. On the basis of an analysis of the literature, it was found that hetherto the construction worker-related analyses focused among others on:

- identifying personnel factors and causes of accidents concerning working with electricity,

- analysing the professional and individual characteristics of accidents casualities,

- determining the professional profile of those most prone to accidents

- studying the impact of external factors (for example vibrations) on the performance of employees,

- determining the dependencies between the age of the casuality and the height from which the terminal fall occurred.

The article analyses the impact of vibrations induced by human activity on the stage on the possibility of a threat to the health of workers working on scaffolding. Scaffoldings are specific structures that are particularly predisposed to vibrations.

As part of the research project "Model of risk assessment of construction disasters, accidents and dangerous occurrences at workplaces with the use of building scaffoldings," dynamic measurements of the scaffolding were conducted. Dynamic measurements rely on a measurement of acceleration at selected points of the scaffolding with various kinds of excitation. The main objective of these studies is to determine the ranges of the accelerations that workers on the scaffolding are exposed to.

\footnotetext{
* Corresponding author: zbigniew.wojcicki@pwr.edu.pl
} 
In accordance with the instructions for field surveys, developed by the research team, the frequency of vibrations at the last level of the scaffolding was measured. Forcing vibrations occurred on the last working level of the scaffolding for each measurement at a different point. At each point three types of excitation were performed: skips (the $z$ direction of the excitation), balancing the body along the facade (the $x$ direction of the excitation), balancing the body perpendicular to the facade (the $y$ direction of the excitation).

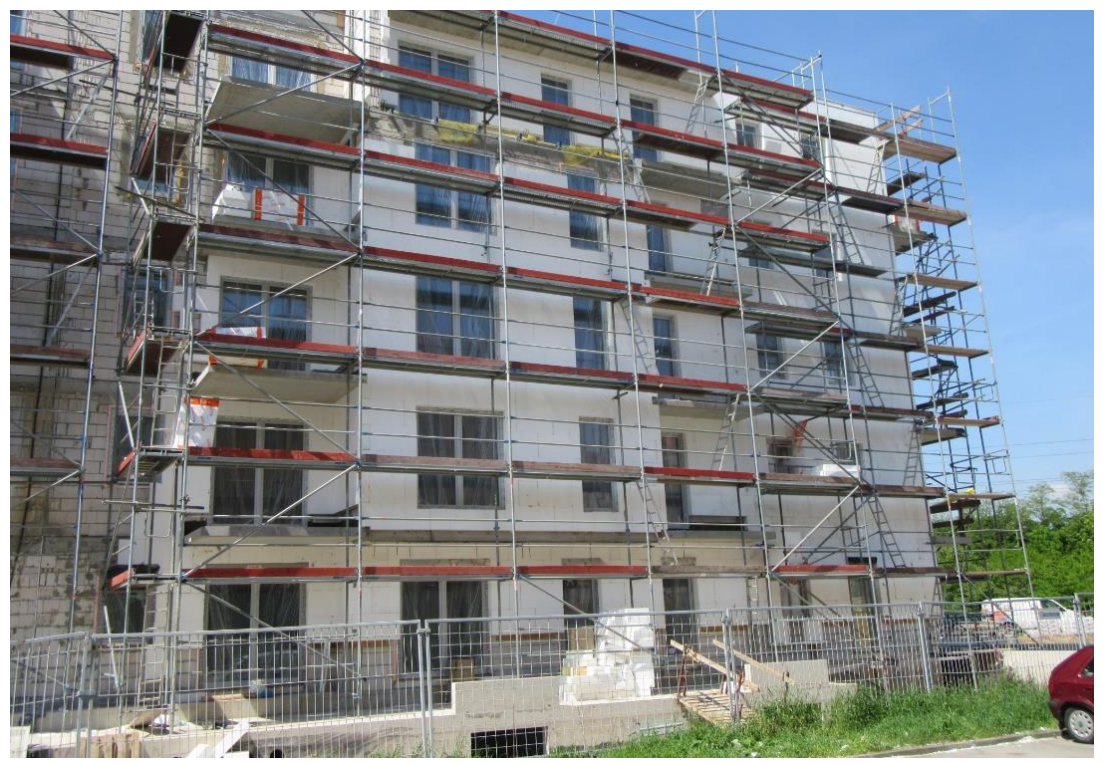

Fig. 1. View of the exemplary scaffolding.

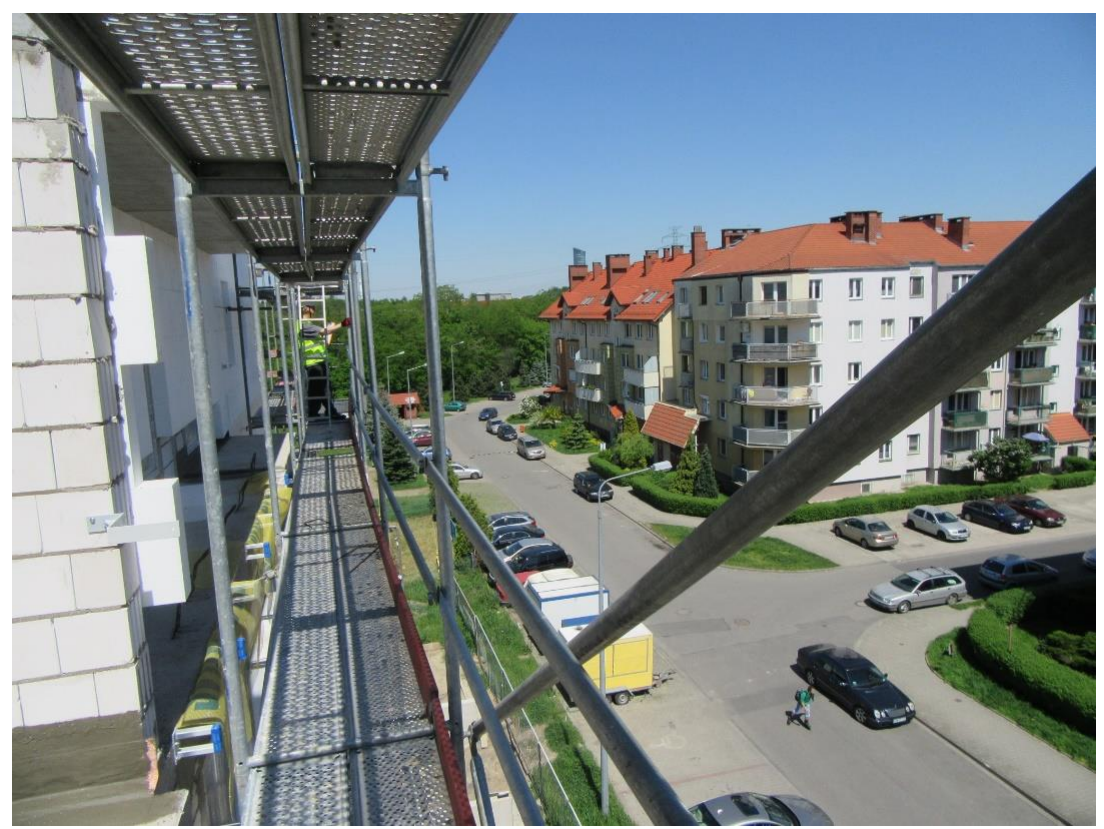

Fig. 2. View of the exemplary scaffolding. 
Analysing the effect of vibration on people working on the scaffolding you can highlight two most important aspects:

- forces giving the greatest amplitude are not stationary but mostly impulse excitation,

- the most common source of vibration sensed by the worker is his own activity (movement, working with electro-tools).

Impulse excitations (the movement of workers, the descent down the ladders, movement of materials) results in the vibration of scaffolds with significant vibration crest factor. In the analysed cases the maximum value of the crest factor was up to 30. Standard [2] allows to analyse the vibration crest factor value not exceeding 6 . Non-stationary signals with a high crest factor value can be analysed in accordance with the guidelines contained in the standards [2] and [3]. Methodology of analysis differs, sometimes quite substantially, in both standards. This study used recommendations and methodology of British standards [3] and the evaluation of vibration based on a parameter VDV (Vibration Dose Value).

\section{Measurements and analysis of the vibration}

\subsection{Brüel \& Kjær's platform for vibration measurements and analysis}

Measurements were carried out by measuring the vibration in three directions simultaneously on the supported part of the scaffolding construction (in the middle of the bridge effects could be larger). Three miniature piezoelectric accelerometers CCLD ThetaShear $^{\circledR}$ with TEDS (Transducer Electronic Data Sheet), type 4507B-005 with high sensitivity and very low weight were used, Figure 3.

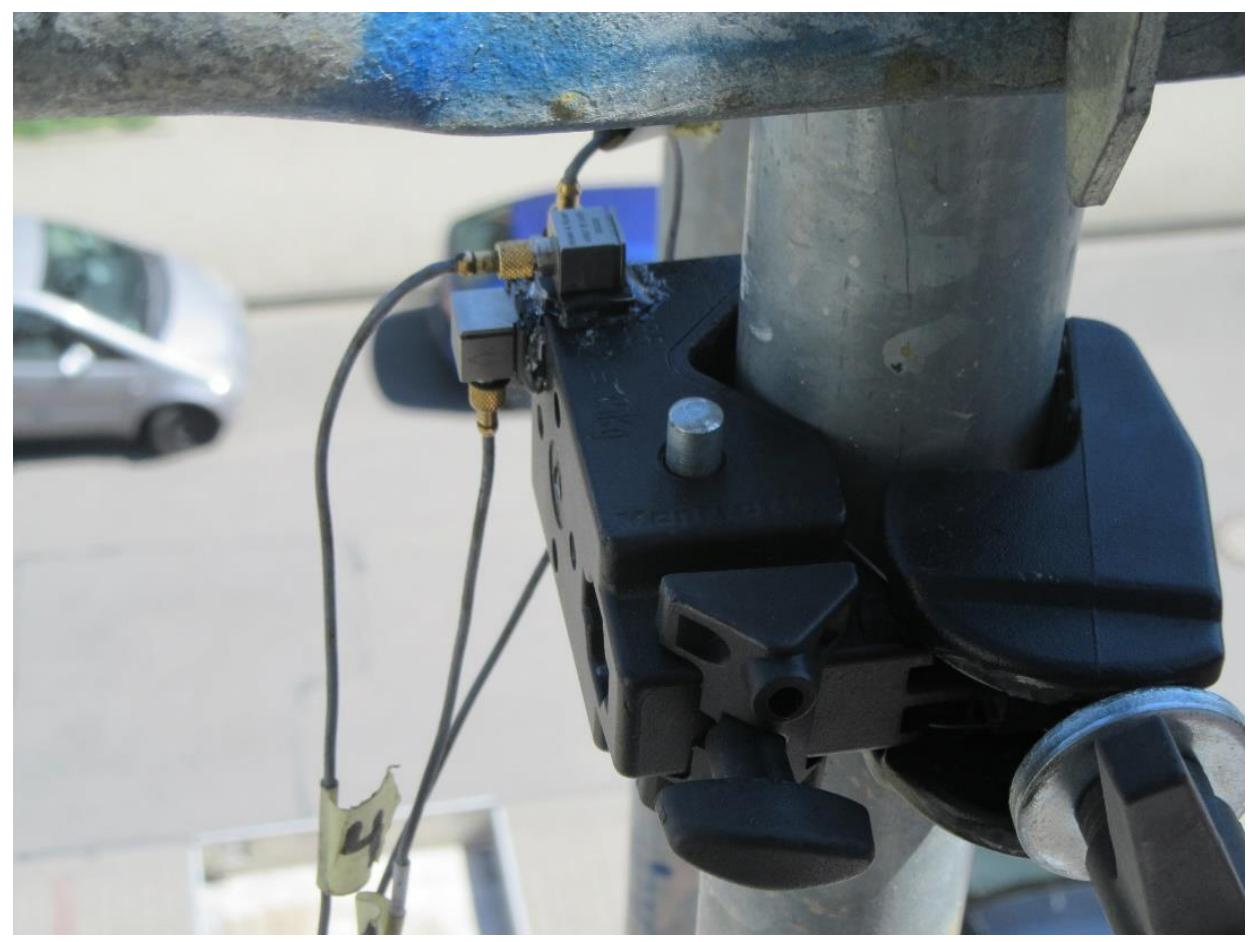

Fig. 3. Acceleration measurements on scaffolding with use of CCLD TEDS ThetaShear ${ }^{\circledR}$ accelerometers type 4507B-005. 
Up to 4 measuring channels recorder LAN-XI Notar ${ }^{\mathrm{TM}}$ - BZ-7848 type 3050-A-040 with battery type 2831-A and registration memory, was used to record time history of scaffolding vibrations, Figure 4.

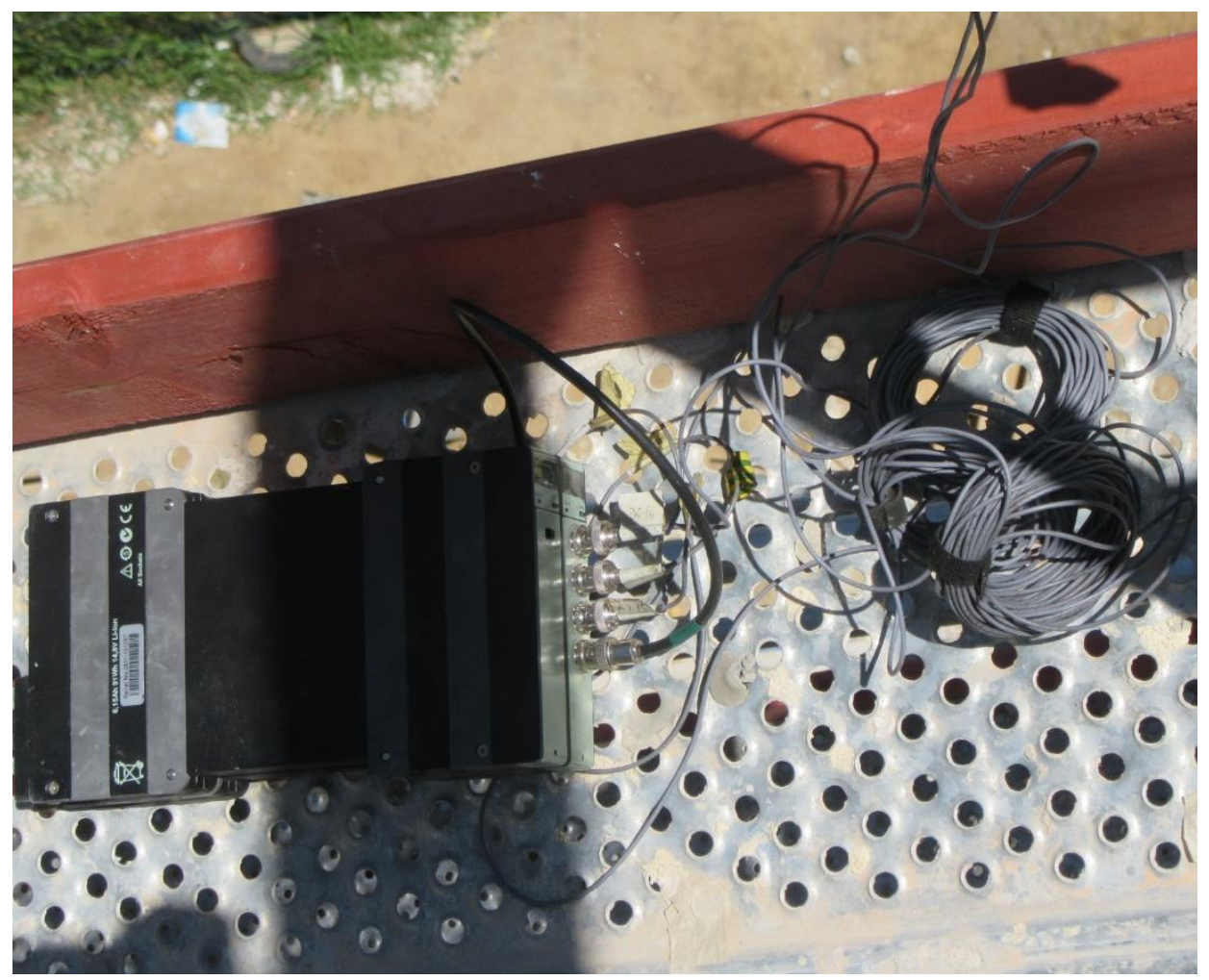

Fig. 4. Acceleration measurements on scaffolding with use LAN-XI Notar ${ }^{\mathrm{TM}}$ recorder.

The vibrations were excited by human activity on the same level of the scaffolding (jumping, swinging etc.).

\subsection{Analysis of vibration levels in accordance with Polish standards}

An example analysis of vibration levels is illustrated in the Figure 5, which shows the third-octave analysis carried out for dominant horizontal direction of vibrations (hatched bars) and for vertical direction (bars uniformly blacked out).

Lines marked standard [4] code limits, respectively: blue ones for vibrations sensed by humans in directions $x, y$, and black one for the vibrations sensed by humans in the $z$ direction. 
Dotted lines (multiplier 1) means the statistical limit of vibration perception for humans- vibrations below this limit are imperceptible to people. Dashed lines (multiplier 8) means the limit of vibration allowable in production areas. The solid lines (multiplier 128) means the limit of vibration allowable in production areas in the case of occasional vibration (no more than 10 times a day). Polish standard [4] cannot be applied to these issues, however, the figure shows the recorded levels of vibration. The vibrations are definitely greater than the threshold of perception and exceed the threshold of comfort for heavy industry (factor 8) - can be felt as annoying or disturbing at work. It is worth noting that according to the standard [4], vibration announced earlier have a higher limit. As the vibrations are mostly caused by the recipient of the vibration, they do not necessarily have to be negatively evaluated by the employee.

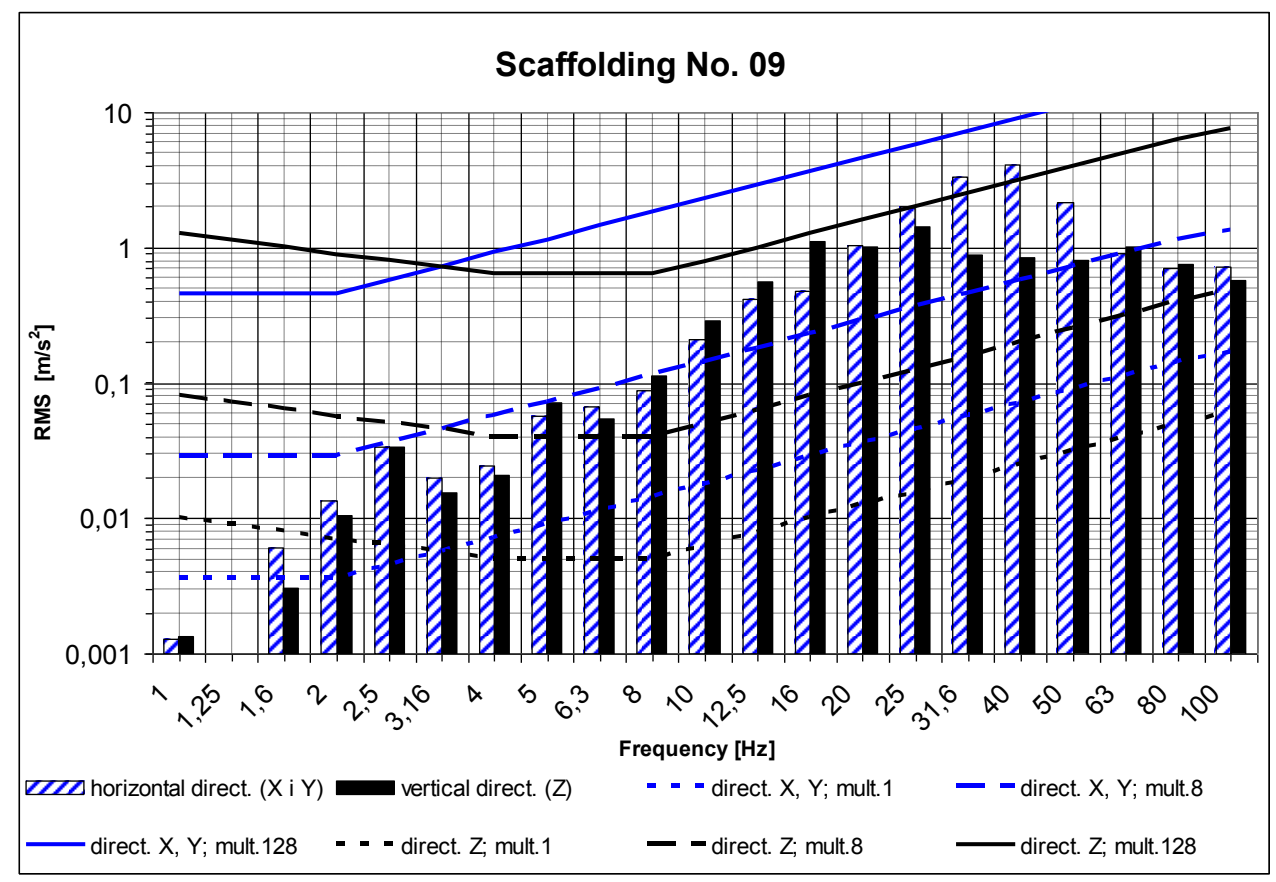

Fig. 5. The third-octave analysis carried out for dominant horizontal and vertical direction.

\subsection{Analysis of vibration levels in accordance with British standard}

The vibrations were evaluated according to standard [3]. The maximum value of the VDV for scaffolding tested ranged from 0.77 to $2.78 \mathrm{~m} / \mathrm{s}^{1,75}$ for a single force incident. According to standard [3] and work [5] a limit value VDV are value 8.5 and $17 \mathrm{~m} / \mathrm{s}^{1,75}$. A value of above 17 means health risk, and a value of above 8.5 means a possible health risk of the employee.

In considering the largest registered value $\operatorname{VDV}\left(2.78 \mathrm{~m} / \mathrm{s}^{1,75}\right)$ exceeding the lower limit occurs after about 100 incidents and exceeding the higher limit - after about 1400 incidents.

\section{Conclusions}

Polish standard [4] cannot be applied to these issues, however, the Fig. 5 shows the recorded levels of vibration. The vibrations are definitely greater than the threshold of 
perception and exceed the threshold of comfort for heavy industry (factor 8) - can be felt as annoying or disturbing at work. It is worth noting that according to the standard [4] vibration earlier announced have an increased limit. As the vibrations are mostly caused by the recipient of the vibration, they do not necessarily have to be negatively evaluated by the employee.

Using standard [2] and [3] different results are obtained.

The high number of incidents needed to exceed the VDV limits suggest that there is no threat to the health of workers working on the scaffolding.

This work is supported by Polish National Centre of Research and Development within Project No. 244388 "Model of risk assessment of construction disasters, accidents and dangerous occurrences at workplaces with the use of building scaffoldings", within the framework of the Applied Research Program on the basis of contract No. PBS3 / A2 / 19/2015

\section{References}

1. Polish Standard, PN-91/N-01354, Drgania. Dopuszczalne wartości przyspieszenia drgań o ogólnym oddziaływaniu na organizm człowieka i metody oceny narażenia

2. International Standard, ISO 2631-1:1997 Mechanical vibration and shock - Evaluation to human exposure to whole-body vibration, General requirements

3. British Standard BS 6841:1987 Guide to measurement and evaluation of human exposure to whole-body mechanical vibration and repeated shock

4. Polish Standard, PN-88/B-02171, Ocena wpływu drgań na ludzi w budynkach.

5. M.J. Griffin, Handbook of human vibration (Academic Press 1990) 